\title{
Transcriptional control of brown adipocyte development and physiological function-of mice and men
}

\author{
Patrick Seale, Shingo Kajimura, and Bruce M. Spiegelman ${ }^{1}$ \\ Dana-Farber Cancer Institute and the Department of Cell Biology, Harvard Medical School, Boston, Massachusetts 02115, USA
}

The last several years have seen an explosion of information relating to the transcriptional control of brown fat cell development. At the same time, new data have emerged that clearly demonstrate that adult humans do indeed have substantial amounts of functioning brown adipose tissue (BAT). Together, these advances are stimulating a reassessment of the role of brown adipose tissue in human physiology and pathophysiology. These data have also opened up exciting new opportunities for the development of entirely novel classes of therapeutics for metabolic diseases like obesity and type 2 diabetes.

Anatomists have recognized two types of adipose tissues for at least 100 years (Cannon and Nedergaard 2004). White fat is of course the more obvious, representing at least $10 \%$ of the body weight of normal, healthy adult humans. White fat tissue is specialized for the storage of chemical energy, with white fat cells capable of both synthesizing triglycerides de novo from glucose and importing fatty acids from the blood. An enormous capacity for expansion of white adipose for energy storage was presumably a key evolutionary adaptation to cope with periods of food shortage. However, in current times, with ready supplies of calorie-dense food and sedentary lifestyles, chronic energy overload has caused a worldwide epidemic of obesity. This is now a formidable public health issue, since obesity is a major risk factor for many diseases, including type 2 diabetes, cardiovascular disease, stroke, hypertension, and many cancers (Bray and Bellanger 2006).

Brown fat, a key thermogenic tissue, is a mammalian adaptation that is most obvious in rodents and infant humans (Cannon and Nedergaard 2004). Since smaller animals usually have a larger surface area to volume ratio, they have a higher risk of hypothermia and hence a greater need for brown fat. Indeed, the existence of significant

[Keywords: PRDM16; FoxC2; brown fat; UCP1; PGC-1 $\alpha$; obesity] ${ }^{1}$ Corresponding author.

E-MAIL bruce_spiegelman@dfci.harvard.edu; FAX (617) 632-5363. Article is online at http://www.genesdev.org/cgi/doi/10.1101/gad.1779209. deposits of brown fat in normal adult humans was doubted until very recently. New data, reviewed here, now put this question to rest, once and for all. The field must now address the relative importance of activated brown fat in explaining differences in susceptibility to obesity and diabetes among human subjects. Likewise, the ability to alter the amount and activity of brown fat holds exciting therapeutic implications for these disorders.

Brown fat tissue is composed of brown fat cells, plus abundant blood vessels and nerves (Fawcett 1952; Cinti 2000). Since brown fat provides heat to the body in response to sympathetic nerve activity, and the heat is carried via the bloodstream, this architecture makes sense. Brown fat cells themselves have a very unique cellular and molecular composition. They are indeed fat cells, having all of the enzymatic machinery to synthesize and store triglyceride; in the case of brown fat cells, lipid is normally stored in multiple small fat droplets (multilocular), as opposed to white fat cells, which usually contain one giant droplet of triglyceride (unilocular). The thermogenic business of brown fat cells is carried out in the very dense mitochondria that these cells possess. In fact, brown fat cells and cardiomyocytes possess the highest levels of mitochondria in mammalian organisms (Scheffler 1999). However, unlike heart cells, which utilize mitochondria to generate the extremely high amounts of ATP needed to perform cardiac contractile function, the mitochondria of brown fat cells uncouple large amounts of fuel oxidation from ATP generation. This uncoupling is caused by the presence of Uncoupling Protein-1 (UCP1), which sits in the inner mitochondrial membrane and catalyzes a leak of protons from the intramembrane space into the mitochondrial matrix (Klingenberg 1999). The resulting dissipation of the mitochondrial membrane potential, along with extremely high rates of mitochondrial electron transport and fuel oxidation, results in the generation of heat and the expenditure of huge amounts of chemical energy.

Brown fat has been well-established as a crucial component in the defense against the cold in a process called nonshivering thermogenesis (Cannon and Nedergaard 2004). Chronic cold exposure of rodents or humans causes an expansion and activation of brown fat (Klingenspor 
2003). Cold is sensed in the central nervous system, and the brown fat is activated via catecholamines secreted by sympathetic nerve terminals in the brown adipose tissue (BAT) itself (Klingenspor 2003; Cannon and Nedergaard 2004). The thermogenic function of brown fat tissue, is, in fact, only functional in response to adrenergic input. Thyroid hormones also play a key role in the sympathetic activation of nonshivering thermogenesis, in part through the stimulation of UCP1 transcription (Bianco and Silva 1987; Ribeiro et al. 2001). Brown fat can also be activated, and can expand quite massively, by constitutive exposure to $\beta$-adrenergic agonists, either pharmacological or due to catecholamine-secreting tumors. In addition to effects on BAT, cold exposure or catecholamines causes the emergence of UCP1-expressing brown fat cells in classic depots of white fat (Ghorbani and Himms-Hagen 1997; Cinti 2005). In the genetic absence of UCP1, mice lose their ability to produce heat by nonshivering thermogenesis and therefore exhibit a profound cold intolerance (Enerback et al. 1997).

Brown fat has also been recognized for its potential and demonstrated anti-obesity properties. Certain diets in rodents that cause overfeeding (cafeteria diets) stimulate the expansion and activation of brown fat, in an apparent physiological effort to restrain weight gain and obesity, so-called diet-induced thermogenesis (Rothwell and Stock 1979). The genetic ablation of BAT via expression of a targeted toxigene causes a propensity toward obesity and metabolic disease (Lowell et al. 1993). Likewise, deletion of UCP1 in mice causes increased weight gain, when mice are housed at thermoneutrality (Feldmann et al. 2009). Indeed UCP1 has now clearly been demonstrated as a key factor in diet-induced thermogenesis. In addition, a large number of genetic studies in mice have shown that experimental increases in the amount and/or function of brown fat promotes a lean and healthy phenotype (Kopecky et al. 1995, 1996; Cederberg et al. 2001; Tsukiyama-Kohara et al. 2001; Xue et al. 2007). Specifically, mice with higher amounts of brown type fat gain less weight, are more insulin-sensitive, have lower levels of serum-free fatty acids, and are protected from diabetes and other metabolic sequelae. Finally, stimulation of brown fat-mediated thermogenesis in adult animals by pharmacological treatment with $\beta$-adrenergic agonists or thyroid receptor agonists does reduce obesity, but thus far, these agents have had too many untoward side-effects to warrant further clinical development (Arch 2002).

\section{Transcriptional control of BAT cell development and differentiation}

Extensive studies in cell culture and in vivo have revealed the molecular pathways that control the process of adipocyte differentiation from preadipocytes (for review, see Farmer 2006; Rosen and MacDougald 2006; Gesta et al. 2007). PPAR $\gamma$ (peroxisome proliferator-activated receptor- $\gamma$ ), a member of the nuclear hormone receptor superfamily, plays the central role in the differentiation of both white and brown fat cells (Tontonoz et al. 1994; Barak et al. 1999; Rosen et al. 1999; Nedergaard et al.
2005). Interestingly, however, mice with a particular mutation in PPAR $\gamma$, P465L, display deficits in brown fat development and thermogenic function but have apparently normal white fat tissue (Gray et al. 2006). Members of the C/EBP family of transcription factors (CCAAT/ enhancer-binding proteins: $\mathrm{C} / \mathrm{EBP} \alpha, \mathrm{C} / \mathrm{EBP} \beta$, and C/EBP $\delta$ ) also participate in activating and maintaining the expression of adipogenesis-induced genes, including PPAR $\gamma$. Increased and sustained expression of $\mathrm{C} / \mathrm{EBP} \beta$ in white fat cells promotes the expression of brown fat cellselective genes (Karamanlidis et al. 2007), though it is expressed and controls initiating adipogenic events in both white and brown fat cells. C/EBP $\alpha$ is a key transcriptional regulator of insulin sensitivity in mature fat cells. PPAR $\gamma$ and $\mathrm{C} / \mathrm{EBP} \alpha$ cooperatively regulate each other's expression and orchestrate a transcriptional cascade that maintains the stable differentiated state of the adipocyte (Wu et al. 1999; Lefterova et al. 2008; Nielsen et al. 2008). However, ectopic expression of PPAR $\gamma$ or C/ EBP $\alpha$ in mesenchymal cells induces only a white, not brown, fat phenotype, suggesting that these molecules do not control the determination of brown fat cell fate. Several recent studies have, however, described transcriptional regulators that positively or negatively influence brown fat development (Fig. 1).

\section{FoxC2 (Forkhead box C2)}

FoxC2, a member of the forkhead/winged helix transcription factor family, promotes brown fat development. In particular, transgenic expression of FoxC2 in adipose tissue induces a remarkable brown fat-like phenotype in white adipose tissue (WAT), with increased expression of thermogenic (such as UCP1) and mitochondrial genes.

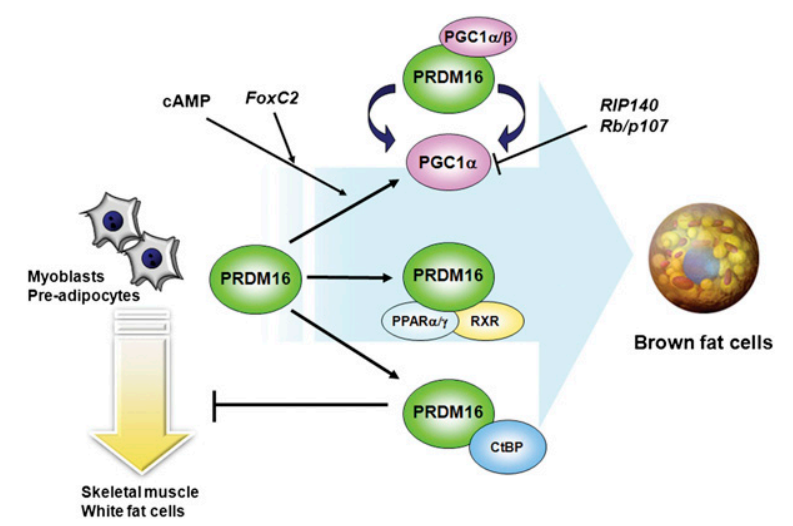

Figure 1. Transcriptional cascades in brown fat development through PRDM16. PRDM16 expression in myoblasts or preadipocytes induces $P G C-1 \alpha$ gene expression. PRDM16 coactivates the transcriptional activity of PGC- $1 \alpha$ and PGC- $1 \beta$ as well as $\operatorname{PPAR} \alpha$ and PPAR $\gamma$ through direct interaction. The cAMPdependent thermogenic program is potentiated by FoxC2 and PRDM16. RIP140, Rb, and p107 antagonize the expression or function of PGC-1 $\alpha$. On the other hand, PRDM16 represses the expression of white fat cell or skeletal muscle-specific genes, mediated through its regulated association with the corepressors CtBP1 and CtBP2. 
Importantly, FoxC2 transgenic mice are lean, insulinsensitive, and resistant to diet-induced obesity (Cederberg et al. 2001; Kim et al. 2005). FoxC2 achieves this "browning" effect, at least in part, by sensitizing cells to the $\beta$-adrenergic cAMP-PKA pathway (Fig. 1). This occurs by directly inducing the expression of the RI $\alpha$ subunit of PKA (Cederberg et al. 2001; Dahle et al. 2002). Interestingly, FoxC2 also activates expression of angiopoietin-2 to stimulate vascularization in adipose tissue, which is also a prominent feature of BAT (Xue et al. 2008). Although FoxC2 is abundantly expressed in adipose tissue, it is equally expressed both in BAT and WAT, at least at the mRNA level. It also remains to be determined whether brown fat differentiation and function displays a genetic requirement for FoxC2.

\section{PGC-1 $\alpha$ (PPAR $\gamma$ coactivator- $1 \alpha)$}

PGC- $1 \alpha$ was first identified as a PPAR $\gamma$-interacting protein from brown fat cells (Puigserver et al. 1998). PGC-1 $\alpha$ expression is highly induced and activated in response to cold exposure, mediated by the PKA-CREB pathway (Herzig et al. 2001; Cao et al. 2004). Over the past 10 years, PGC- $1 \alpha$ has emerged as a dominant regulator of mitochondrial biogenesis and oxidative metabolic pathways in many cell types via its coactivation of various transcription factors (Lin et al. 2005; Finck and Kelly 2006; Handschin and Spiegelman 2006; Rosen and MacDougald 2006). Indeed, ectopic expression of PGC-1 $\alpha$ in white fat cells induces a number of mitochondrial genes and thermogenic genes, including UCP1 (Puigserver et al. 1998; Tiraby et al. 2003).

Notably, several molecules have been shown to influence brown fat development and function, at least in part, through regulating the expression or transcriptional activity of PGC-1 $\alpha$. For example, RIP140, a corepressor of many nuclear receptors, directly binds PGC- $1 \alpha$ and antagonizes its transcriptional function on several target gene promoters shared by PGC-1 $\alpha$ and RIP140 (Hallberg et al. 2008). Expression of RIP140 in adipose and skeletal muscle represses mitochondrial biogenesis and oxidative metabolism (Leonardsson et al. 2004; Christian et al. 2005; Powelka et al. 2006; Seth et al. 2007). Genetic ablation of RIP140 causes the emergence of brown fat-like cells in WAT (Leonardsson et al. 2004). Although RIP140 expression is slightly enriched in WAT compared with BAT, quantitative increases in RIP140 expression has not been demonstrated to preferentially favor the differentiation of white adipocytes.

The SRC (steroid receptor coactivator) family members, including SRC-1/NcoA1, SRC-2/TIF2/GRIP1, and SRC-3/p/CIP, have distinct and overlapping functions in controlling energy metabolism and brown fat development (Louet and O'Malley 2007). SRC-1 knockout mice exhibit impaired adaptive thermogenesis with reduced UCP1 expression in BAT (Picard et al. 2002). In contrast, $S R C-2$ knockout mice display improved energy expenditure and higher adaptive thermogenesis. SRC-2 inhibits the interaction of PPAR $\gamma$ with PGC- $1 \alpha$, whereas SRC-1 reinforces the coactivation of PGC- $1 \alpha$ on PPAR $\gamma$ tran- scriptional activity (Picard et al. 2002). SRC-3-deficient BAT has smaller lipid droplets with higher mitochondrial content. Interestingly, SRC-3 induces GCN5, the major acetyltransferase of PGC- $1 \alpha$ (Lerin et al. 2006), to repress the transcriptional activity of PGC- $1 \alpha$. Ablation of SRC-3 reduces acetylation of PGC- $1 \alpha$, leading to an increase in mitochondrial biogenesis (Louet et al. 2006; Coste et al. 2008).

Adipocytes from retinoblastoma protein $(p R b)$-deficient fibroblasts or embryonic stem cells exhibit a brown-fat phenotype with high mitochondrial content, and elevated expression of UCP1,PGC-1 $\alpha$, and mitochondrial genes (Hansen et al. 2004). Since most $p R B$ knockout mice are embryonic lethal due to abnormalities in neural and hematopoietic development (Clarke et al. 1992; Jacks et al. 1992; Lee et al. 1992), whether BAT development in vivo requires $\mathrm{pRb}$ is unknown. WAT from mice lacking p107, another member of $\mathrm{Rb}$ pocket protein family, contains abundant brown fat-like cells with multilocular oil droplets (Scime et al. 2005). These adipose tissues are enriched in mitochondria with high levels of UCP1 and PGC-1 $\alpha$ gene expression. Notably, $\mathrm{pRb}$ levels are dramatically reduced in p107-deficient Sca- $1^{+} \mathrm{CD} 31^{-} \mathrm{Lin}^{-}$adipogenic precursors, suggesting that the $\mathrm{p} 107$ action is mediated through regulation of $\mathrm{pRb}$. Interestingly, $\mathrm{pRb}$ has been shown to directly bind the $P G C-1 \alpha$ promoter to repress its transcription (Scime et al. 2005).

Taken together, these data had suggested a dominant role for PGC- $1 \alpha$ in brown fat development and function. Indeed, genetic ablation of $P G C-1 \alpha$ results in greatly reduced capacity for cold-induced adaptive thermogenesis (Lin et al. 2004). This is indeed a cell-autonomous requirement for PGC-1 $\alpha$ in BAT cells, since immortalized brown fat cells lacking PGC- $1 \alpha$ display a blunted induction of thermogenic genes in response to cAMP /Uldry et al. 2006). However, many non-cAMP-dependent brown fat cell-selective genes are still expressed appropriately, and the fat differentiation program itself is unaltered in the absence of PGC-1 $\alpha$. These results suggest that while PGC- $1 \alpha$ is a crucial regulator of adaptive thermogenesis, it is not an essential determinant of brown fat identity.

\section{PRDM16 (PRD1-BF-1-RIZ1 homologous \\ domain-containing protein-16)}

In a genome-wide survey of all known and putative transcriptional regulators in the mouse genome, PRDM16 was identified as one of only three genes whose expression correlated strongly with the brown fat phenotype in vivo and in cultured cell models (Seale et al. 2007). PRDM16 was originally identified at a chromosomal breakpoint of $\mathrm{t}(1 ; 3)(\mathrm{p} 36 ; \mathrm{q} 21)$-positive human acute myeloid leukemia cells (Mochizuki et al. 2000; Nishikata et al. 2003). PRDM16 contains seven repeats of $\mathrm{C} 2 \mathrm{H} 2$ zinc-finger domain at its $\mathrm{N}$ terminus (ZF1 domain) and three similar repeats at its $\mathrm{C}$ terminus (ZF2 domain). PRDM16 also contains a putative SET domain, a conserved region among histone lysine methyltransferases (Rea et al. 2000; Schultz et al. 2002; Trievel et al. 2002). An aberrant form of PRDM16 
lacking the SET domain is expressed selectively in adult T-cell leukemia cells (Yoshida et al. 2004). This short form of PRDM16 has been suggested to transform cells by interfering with the function of the full-length protein (Du et al. 2005; Shing et al. 2007). Whether multiple spliced forms of PRDM16 exist in brown adipocytes and what their functional role in this cell type is remain unknown.

When ectopically expressed in cultured mesenchymal cells including white fat preadipocytes, PRDM16 induces a complete program of brown fat differentiation, including activation of thermogenic genes (UCP1, PGC-1 $\alpha$, and Deiodinase-d2), mitochondrial genes, and other BATselective genes (cidea and elovl3) (Fig. 1; Seale et al. 2007, 2008; Kajimura et al. 2008). Furthermore, transgenic expression of PRDM16 in adipose tissue induces the formation of copious clusters of UCP1-expressing brown adipocytes in WAT depots. Importantly, PRDM16expressing cells display high levels of uncoupled cellular respiration in response to CAMP, as do authentic brown fat cells.

Although PRDM16 has been shown to bind directly to a specific DNA sequence via two sets of zinc-fingers (ZF1 and ZF2) in vitro (Nishikata et al. 2003), abrogation of DNA binding by introducing a point mutation in ZF2 does not alter the ability of PRDM16 to induce a brown fat phenotype (Seale et al. 2007). This result suggests that the action of PRDM16 is largely mediated by protein-protein interactions, rather than by direct DNA binding. In fact, PRDM16 powerfully coactivates the transcriptional activity of PGC- $1 \alpha$ and PGC- $1 \beta$, as well as PPAR $\alpha$ and $\operatorname{PPAR} \gamma$, through direct physical interaction (Fig. 1; Seale et al. 2007, 2008). Presumably, PRDM16 also interacts with other transcription factors yet to be defined.

Intriguingly, coincident with the induction of brown fat cell-selective genes, PRDM16 expression is also associated with the suppression of several markers selective for white fat cells (such as resistin and angiotensinogen) or muscle (myoD, myogenin, and myosin heavy chain). The repressive action of PRDM16 on white fat cell-selective genes is mediated by its regulated association with the corepressors, CtBP1 and 2 (Kajimura et al. 2008). The DNA-binding protein(s), however, through which PRDM16 functions to suppress transcription of these genes remains to be identified.

Finally, PRDM16 is required for the identity and function of brown fat cells both in vitro and in vivo. Depletion of PRDM16 from cultured brown fat cells causes a near total loss of the brown fat characteristics (Seale et al. 2007). Surprisingly, the complete loss of PRDM16 from cultures of primary brown fat cell precursors promotes overt skeletal muscle differentiation. Consistent with this, BAT from PRDM16-deficient mice at embryonic day 17 exhibits an abnormal morphology with dramatically reduced expression of thermogenic genes and elevated expression of muscle-specific genes (Seale et al. 2008). Taken together, these results establish PRDM16 as a critical determinant of the brown fat lineage.

\section{Embryonic origin of brown fat}

White and brown adipocytes have long been assumed to share a common developmental origin because they express a common array of genes involved in triglyceride metabolism. They also undergo a very similar program of morphological differentiation controlled by PPAR $\gamma$ and members of the C/EBP family of transcription factors (Rosen and Spiegelman 2000; Hansen and Kristiansen 2006; Gesta et al. 2007). Recent studies, however, have surprisingly indicated that brown and white fat cells, in fact, arise from distinct cellular lineages. Elegant lineage tracing experiments by Atit et al. (2006) showed that BAT, dermis, and some skeletal muscles are derived from a population of Engrailed-1 (En1)-expressing cells in the dermamyotome (Fig. 2). Moreover, microarray experiments revealed that brown but not white fat precursors express many genes and microRNAs that are characteristic of muscle precursors (Timmons et al. 2007; Walden et al. 2009). In a completely independent line of investigation, as noted above, we found that depletion of PRDM16 from cultures of primary brown fat precursors induces skeletal muscle differentiation (Seale et al. 2008). Moreover, ectopic expression of PRDM16 in committed myoblasts, both immortalized and primary, caused the cells to adopt a brown fat phenotype when exposed to proadipogenic stimuli (Seale et al. 2008). PRDM16 can

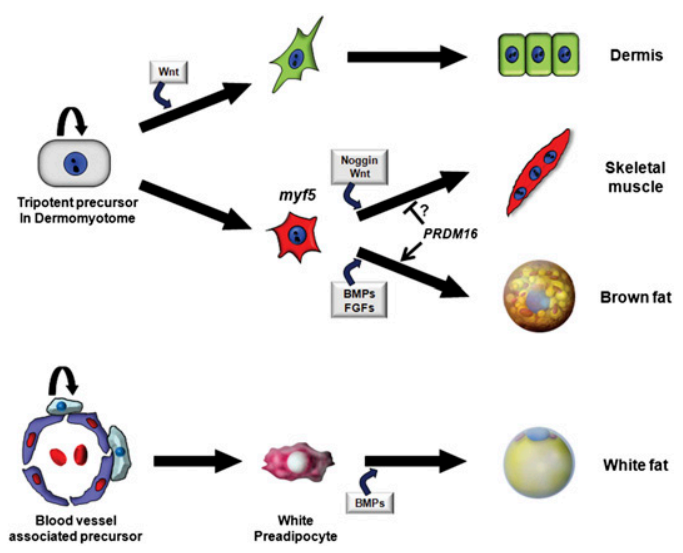

Figure 2. Model for PRDM16 function in specifying brown fat versus skeletal muscle cell fate. Lineage tracing experiments suggest a model in which tripotent, Engrailed-1-expressing cells in the central dermomyotome give rise to dermis, epaxial muscle, and brown fat. Wnt signals appear to direct these precursor cells to the dermal fate (Atit et al. 2006). Brown fat and skeletal muscle arise from precursor cells that have expressed Myf5, a gene that has been assumed to selectively mark skeletal myogenic progenitors. Gain-of-function and lossof-function experiments suggest that PRDM16 specifies brown fat cell identity from "myoblast-like" precursors by activating brown adipogenesis and suppressing skeletal myogenesis. The cues that control PRDM16 expression in the presumptive brown fat/skeletal muscle precursors are unknown. By contrast, white fat cells belong to a completely independent cell lineage. A recent report suggests that at least some precursors for white fat cells are derived from mural cells associated with blood vessels (Tang et al. 2008). 
thus apparently control a bidirectional cell fate switch between muscle and brown fat.

To more closely examine whether the BAT and skeletal muscle lineages could be developmentally related in an in vivo context, we traced the ontogeny of $M y f 5$-expressing cells in mice. Myf5 is a crucial early myogenic transcription factor whose expression had been thought to be highly specific to committed skeletal myoblastic cells (Pownall et al. 2002). In these studies, we observed that only skeletal muscle and BAT are derived from cells that have previously activated Myf5 (Fig. 2). Importantly, white fat from several depots and all other tissues examined had not been formed from a Myf5-expressing cell lineage. These experiments thus reveal that white and brown fat cell lineages have disparate developmental origins. Consistent with this notion, a new report by Graff and colleagues (Tang et al. 2008) indicates that at least some white adipose precursors derive from mural cells (pericytes) associated with blood vessels in adipose (Fig. 2).

The Myf5-lineage tracing studies suggest that brown fat is derived from a precursor cell type that is equipped with the potential to give rise to brown fat and muscle. Notably, myogenin-deficient mice that are devoid of differentiated skeletal muscle fibers have prominent deposition of brown fat tissue especially in the dorsal cervival region (Hasty et al. 1993), suggesting that cells incapable of completing terminal muscle differentiation give rise to brown fat cells. However, the identity of this "putative" brown fat/skeletal muscle progenitor cell population remains to be localized and characterized in mouse embryogenesis. The lineage tracing studies do not dismiss the possibility that distinct pools of Myf5expressing precursors exist that are committed to either muscle or brown fat

Interestingly, the pockets of brown fat cells that emerge in white fat depots in response to chronic $\beta$-adrenergic stimulation were not derived from a Myf5-expressing cell lineage (Seale et al. 2008). Notably, Kozak's group (Xue et al. 2007) had shown previously that BAT cells in the interscapular depot and those localized in WAT depots are genetically distinct.We speculate that the brown fatlike cells in WAT tissues possess a more plastic phenotype, enabling them to adapt to environmental cues, whereas the distinct depots of brown fat cells that are present before birth are stably committed to the brown fat fate. It remains to be determined which cell type(s) in white fat tissues are able to give rise to UCP1-expressing brown type adipocytes. It is possible that certain white fat preadipocytes or mature white fat cells can be stimulated to undergo brown adipogenesis. Alternatively, a distinct population of committed brown fat precursors or other more primitive stem cells may reside in WATs. Although we hypothesize that PRDM16 is involved in the formation of these brown-type fat cells in vivo, this has yet to be examined. Interestingly, brown fat cells and their precursors have been localized in mouse and human skeletal muscle tissue and may be protective against metabolic disease (Almind et al. 2007; Crisan et al. 2008). Whether these cells arise from Myf5+ myoblastic cells has not yet been established.
It will now be important to carefully map the embryonic expression pattern of PRDM16 in an effort to pinpoint the putative brown fat-skeletal muscle precursors. In addition, signaling molecules that control the timing and specificity of PRDM16 expression during development are unknown. Certain growth factors have been shown to influence both brown and white adipogenesis. Of particular note, bone morphogenetic proteins (BMPs) have emerged as powerful regulators of both white and brown adipocyte differentiation (Sottile and Seuwen 2000; Hata et al. 2003; Tang et al. 2004; Taha et al. 2006; Tseng et al. 2008). Consistent with a crucial role for BMP signaling in adipogenesis, mice lacking Schnurri-2, an important mediator of the BMP pathway, have profound deficits in adipose tissue development (Jin et al. 2006). Notably, BMP2 and BMP4 have been shown to promote the differentiation of white adipose cells, whereas BMP7 selectively stimulates the process of brown adipogenesis in committed precursors. In particular, exposure of brown preadipocytes to BMP7 induces a full program of brown fat differentiation, including induction of PRDM16 and UCP1 expression (Tseng et al. 2008). Moreover, BMP7-deficient mice display a profound deficit in the development of brown fat tissue (Tseng et al. 2008). It is not known, however, if BMP7 plays a direct role in inducing or activating PRDM16. In addition, the transcriptional components in preadipocytes that control the differential adipogenic response to various BMPs remain to be found. Interestingly, BMPs have also been shown to negatively regulate myogenesis in certain contexts (Murray et al. 1993; Katagiri et al. 1997; Reshef et al. 1998), identifying them as potential candidates for controlling brown adipogenic versus skeletal muscle cell fate (Fig. 2).

Activation of the canonical Wnt (wingless) signaling pathway has been shown to inhibit both brown and white adipogenesis by blocking the induction of $P P A R \gamma$ and $C /$ $E B P \alpha$ (Ross et al. 2000; Bennett et al. 2002; Longo et al. 2004; Kang et al. 2005; Li et al. 2008). Wnt10a and $W n t 10 b$ are expressed in brown fat tissue and are downregulated during in vitro differentiation of brown fat preadipocytes. In mature brown fat cells, ectopic Wnt10b expression inhibits the expression of $P G C-1 \alpha$ and thereby promotes a white fat phenotype (Longo et al. 2004; Kang et al. 2005). Wnt signaling is also an important promyogenic cue during embryogenesis and adult muscle regeneration (Cossu and Borello 1999; Polesskaya et al. 2003; Otto et al. 2008). As with the BMPs, the reciprocal effects of Wnt signaling in adipogenesis and myogenesis suggest that it could also play an instructive role in presumptive precursors for brown fat and skeletal muscle.

Members of the fibroblast growth factors (FGFs) have also been suggested to play developmental and functional roles in brown adipogenesis. FGF16 is highly expressed in growing BAT tissue during late stages of fetal development and decreases postnatally (Konishi et al. 2000). In cell culture assays, recombinant FGF16 stimulates the proliferation of BAT preadipocytes. Transgenic expression of FGF19 (FGF15 in mouse) in skeletal muscle causes an expansion of BAT and elevated whole-body energy 
expenditure; however, whether this effect is a direct endocrine action of FGF19 is not known (Tomlinson et al. 2002).

\section{Brown fat tissue and thermogenesis in adult humans}

The prevailing dogma that BAT is not present to significant levels in adult humans has now been refuted. Positron emission tomography (PET) is used diagnostically to detect cancer tissues/cells based on their capacity to take up large amounts of ${ }^{18}$ fluoro-labeled 2-deoxyglucose (FDG). During the course of these imaging studies, symmetrically distributed hot spots for FDG uptake were noted that had the characteristic density of adipose tissue (Hany et al. 2002; Yeung et al. 2003; Tatsumi et al. 2004; Weber 2004; Alkhawaldeh and Alavi 2008). Moreover, the incorporation of FDG in these tissues disappeared when patients were kept warm. Altogether, a large number of such reports had strongly suggested that these tissues were in fact BAT (Nedergaard et al. 2007). These reports, however, were largely overlooked by the metabolism/obesity community because they were published in very specialized medical journals. Very recently, the nature of these putative brown fat depots in adult humans has been carefully examined by dedicated FDG-PET analyses, combined with tissue biopsies. Most importantly, by all criteria, these tissues are now unequivocally identified as thermogenic brown fat (S. Enerback and C.R Kahn, pers. comm.). Most importantly, the results of Enerback and colleagues (S. Enerback, pers. comm.) clearly demonstrate in the same subjects that human BAT is dramatically activated by cold exposure. The human brown fat depots are localized in the supraclavicular, cervical, and paravertebral regions and express high levels of PRDM16, PGC-1 $\alpha$, and UCP1. Analysis of a large number of historical FDG-PET scans by Kahn and colleagues (C.R. Kahn, pers. comm.) suggests an inverse correlation between BAT volume and BMI (Body mass index). Based on the amount of active BAT detected by these studies, it seems very likely that these tissues may make an important contribution to whole-body energy balance. However, because the detection of BAT by FDG-PET is so temperature-sensitive, dedicated studies to examine the relationship between obesity and BAT activity under standardized conditions are needed. Taken together, these seminal studies have revitalized interest in BAT as an important metabolic tissue in humans.

\section{New therapeutic opportunities}

The expanding epidemic of obesity and diabetes linked to obesity serves clear notice that medical treatments for obesity have not been particularly effective. In addition, a growing understanding that obesity is also driving large increases in the rates of certain cancers, arthritic conditions, and cardiovascular disorders makes the development of new therapeutic approaches to obesity an absolute priority.

Any effective treatment for obesity must fundamentally impact whole-body energy balance, either by re- ducing energy intake from food or increasing energy expenditure. Understanding the complex genetic, behavioral, and environmental networks that regulate food intake and satiety is an enormous and important area of study that has been reviewed elsewhere. Conceptually, at least, the possibility of raising energy expenditure could be achieved by increasing the amount of brown fat. Brown fat evolved for the sole purpose of safely dissipating large amounts of chemical energy. Hence, enhancing the inherent metabolic inefficiency of brown fat cells would be an effective strategy to burn off excess calories. Given the fact that most obese people are not that far out of energy balance, the amount of activated BAT necessary to achieve long-term weight control should not require excessive or unacceptable heat generation.

Given the new knowledge that PRDM16 can act as a dominant regulator of brown fat cell determination, how can this factor and related pathways be used to create new therapies for obesity and linked metabolic diseases? Development of drugs that elevate PRDM16 expression in myoblasts or white preadipocytes in vivo may be possible. The PRDM16 gene is dynamically regulated, showing an increase in determined brown fat precursor cells, relative to white fat precursors or myoblastic cells. PRDM16 is further increased during the process of brown fat cell differentiation in culture. Hence, it is probably worthwhile to screen chemical libraries, as well as collections of known drugs and drug-like compounds, to determine if synthetic chemicals can be found that can activate PRDM16 expression. The target cells for such a therapy would presumably be the myoblastic precursors in postnatal skeletal muscle, as well as the preadipoctyes resident in the white fat tissues.

Furthermore, it is highly likely that PRDM16 is induced in the dermomyotome during brown fat cell determination in the embryo, in response to biological cues that have not yet been identified. If a growth/differentiation factor is involved in this transformation, the same factor could have therapeutic potential postnatally. These studies may not only find new chemical matter with therapeutic potential, but they should also identify biochemical pathways that control PRDM16 expression. Having precise molecular targets that can alter PRDM16 expression within cells could open the door to more precisely targeted drugs. BMP7, which can promote PRDM16 expression and brown adipogenesis in culture and in vivo, may be of direct therapeutic benefit for obesity and type 2 diabetes (Tseng et al. 2008). The full potential of therapies using BMP7 remains to be fully explored. It should also be noted that the thiazolidinediones, which are highly selective PPAR $\gamma$ agonists that act as insulin sensitizing agents, are thought to function, in part, by enhancing a brown adipose phenotype in WAT (Wilson-Fritch et al. 2004; Hondares et al. 2006).

One caveat to these approaches is that we know very little about the function of PRDM16 in nonadipose tissues. Certain human leukemias have a chromosomal translocation in lymphocytes that results in overexpression of PRDM16 (Mochizuki et al. 2000; Nishikata et al. 2003; Shing et al. 2007; Modlich et al. 2008). Obviously, 
synthetic drugs or natural compounds that elevate PRDM16 globally will have to be carefully analyzed for both benefits and toxicities.

A different approach would be to utilize cellular transplantation of modified cells. Adipose tissues are removed from many patients during liposuction; other patients have adipose tissues injected in cosmetic surgery. Thus, it should be feasible to grow either adipose of muscle precursor cells from a given obese patient in culture and stably express PRDM16 in these cells to make them essentially brown fat precursors. Similar approaches could also be attempted by exposing cells to BMP7 or by overexpressing FoxC2. These engineered cells can be injected back into the same patients and, at least in principle, increase whole-body energy expenditure. Among the serious questions we must ask, however, is where such autologous transplants should be placed anatomically in order to optimize their establishment and proper vascularization and innervation. Whether a therapeutic effect via such engineered autologous transplantations would require a thimbleful or a bucketful of cells remains to be determined.

\section{Acknowledgments}

P.S. is supported by an NIH grant (DK081605). S.K. is supported by a fellowship from the Japan Society for the Promotion of Science. This work is funded by the Picower foundation and an NIH grant to B.M.S (DK081605).

\section{References}

Alkhawaldeh, K. and Alavi, A. 2008. Quantitative assessment of FDG uptake in brown fat using standardized uptake value and dual-time-point scanning. Clin. Nucl. Med. 33: 663-667.

Almind, K., Manieri, M., Sivitz, W.I., Cinti, S., and Kahn, C.R. 2007. Ectopic brown adipose tissue in muscle provides a mechanism for differences in risk of metabolic syndrome in mice. Proc. Nat1. Acad. Sci. 104: 2366-2371.

Arch, J.R. 2002. $\beta(3)$-Adrenoceptor agonists: Potential, pitfalls and progress. Eur. J. Pharmacol. 440: 99-107.

Atit, R., Sgaier, S.K., Mohamed, O.A., Taketo, M.M., Dufort, D., Joyner, A.L., Niswander, L., and Conlon, R.A. 2006. $\beta$-Catenin activation is necessary and sufficient to specify the dorsal dermal fate in the mouse. Dev. Biol. 296: 164-176.

Barak, Y., Nelson, M.C., Ong, E.S., Jones, Y.Z., Ruiz-Lozano, P., Chien, K.R., Koder, A., and Evans, R.M. 1999. PPAR $\gamma$ is required for placental, cardiac, and adipose tissue development. Mol. Cell 4: 585-595.

Bennett, C.N., Ross, S.E., Longo, K.A., Bajnok, L., Hemati, N., Johnson, K.W., Harrison, S.D., and MacDougald, O.A. 2002. Regulation of Wnt signaling during adipogenesis. J. Biol. Chem. 277: 30998-31004.

Bianco, A.C. and Silva, J.E. 1987. Intracellular conversion of thyroxine to triiodothyronine is required for the optimal thermogenic function of brown adipose tissue. J. Clin. Invest. 79: 295-300.

Bray, G.A. and Bellanger, T. 2006. Epidemiology, trends, and morbidities of obesity and the metabolic syndrome. Endocrine 29: 109-117.

Cannon, B. and Nedergaard, J. 2004. Brown adipose tissue: Function and physiological significance. Physiol. Rev. 84: 277-359.
Cao, W., Daniel, K.W., Robidoux, J., Puigserver, P., Medvedev, A.V., Bai, X., Floering, L.M., Spiegelman, B.M., and Collins, S. 2004. p38 mitogen-activated protein kinase is the central regulator of cyclic AMP-dependent transcription of the brown fat uncoupling protein 1 gene. Mol. Cell. Biol. 24: 3057-3067.

Cederberg, A., Gronning, L.M., Ahren, B., Tasken, K., Carlsson, P., and Enerback, S. 2001. FOXC2 is a winged helix gene that counteracts obesity, hypertriglyceridemia, and diet-induced insulin resistance. Cell 106: 563-573.

Christian, M., Kiskinis, E., Debevec, D., Leonardsson, G., White, R., and Parker, M.G. 2005. RIP140-targeted repression of gene expression in adipocytes. Mol. Cell. Biol. 25: 9383-9391.

Cinti, S. 2000. Anatomy of the adipose organ. Eat. Weight Disord. 5: 132-142.

Cinti, S. 2005. The adipose organ. Prostaglandins Leukot. Essent. Fatty Acids 73: 9-15.

Clarke, A.R., Maandag, E.R., van Roon, M., van der Lugt, N.M., van der Valk, M., Hooper, M.L., Berns, A., and te Riele, H. 1992. Requirement for a functional Rb-1 gene in murine development. Nature 359: 328-330.

Cossu, G. and Borello, U. 1999. Wnt signaling and the activation of myogenesis in mammals. EMBO J. 18: 6867-6872.

Coste, A., Louet, J.F., Lagouge, M., Lerin, C., Antal, M.C., Meziane, H., Schoonjans, K., Puigserver, P., O'Malley, B.W., and Auwerx, J. 2008. The genetic ablation of SRC-3 protects against obesity and improves insulin sensitivity by reducing the acetylation of PGC-1 $\alpha$. Proc. Natl. Acad. Sci. 105: 1718717192.

Crisan, M., Casteilla, L., Lehr, L., Carmona, M., Paoloni-Giacobino, A., Yap, S., Sun, B., Leger, B., Logar, A., Penicaud, L., et al. 2008. A reservoir of brown adipocyte progenitors in human skeletal muscle. Stem Cells 26: 2425-2433.

Dahle, M.K., Gronning, L.M., Cederberg, A., Blomhoff, H.K., Miura, N., Enerback, S., Tasken, K.A., and Tasken, K. 2002. Mechanisms of FOXC2- and FOXD1-mediated regulation of the RI $\alpha$ subunit of cAMP-dependent protein kinase include release of transcriptional repression and activation by protein kinase B $\alpha$ and cAMP. J. Biol. Chem. 277: 2290222908.

Du, Y., Jenkins, N.A., and Copeland, N.G. 2005. Insertional mutagenesis identifies genes that promote the immortalization of primary bone marrow progenitor cells. Blood 106: 3932-3939.

Enerback, S., Jacobsson, A., Simpson, E.M., Guerra, C., Yamashita, H., Harper, M.E., and Kozak, L.P. 1997. Mice lacking mitochondrial uncoupling protein are cold-sensitive but not obese. Nature 387: 90-94.

Farmer, S.R. 2006. Transcriptional control of adipocyte formation. Cell Metab. 4: 263-273.

Fawcett, D.W. 1952. A comparison of the histological organization and cytochemical reactions of brown and white adipose tissues. J. Morphol. 90: 363-405.

Feldmann, H.M., Golozoubova, V., Cannon, B., and Nedergaard, J. 2009. UCP1 ablation induces obesity and abolishes dietinduced thermogenesis in mice exempt from thermal stress by living at thermoneutrality. Cell Metab. 9: 203-209.

Finck, B.N. and Kelly, D.P. 2006. PGC-1 coactivators: Inducible regulators of energy metabolism in health and disease. $I$. Clin. Invest. 116: 615-622.

Gesta, S., Tseng, Y.H., and Kahn, C.R. 2007. Developmental origin of fat: Tracking obesity to its source. Cell 131: 242-256.

Ghorbani, M. and Himms-Hagen, J. 1997. Appearance of brown adipocytes in white adipose tissue during CL 316,243induced reversal of obesity and diabetes in Zucker fa/fa rats. Int. J. Obes. Relat. Metab. Disord. 21: 465-475. 
Gray, S.L., Dalla Nora, E., Backlund, E.C., Manieri, M., Virtue, S., Noland, R.C., O'Rahilly, S., Cortright, R.N., Cinti, S., Cannon, B., et al. 2006. Decreased brown adipocyte recruitment and thermogenic capacity in mice with impaired peroxisome proliferator-activated receptor (P465L PPAR $\gamma$ ) function. Endocrinology 147: 5708-5714.

Hallberg, M., Morganstein, D.L., Kiskinis, E., Shah, K., Kralli, A., Dilworth, S.M., White, R., Parker, M.G., and Christian, M. 2008. A functional interaction between RIP140 and PGC-1 $\alpha$ regulates the expression of the lipid droplet protein CIDEA. Mol. Cell. Biol. 28: 6785-6795.

Handschin, C. and Spiegelman, B.M. 2006. Peroxisome proliferatoractivated receptor $\gamma$ coactivator 1 coactivators, energy homeostasis, and metabolism. Endocr. Rev. 27: 728-735.

Hansen, J.B. and Kristiansen, K. 2006. Regulatory circuits controlling white versus brown adipocyte differentiation. Biochem. J. 398: 153-168.

Hansen, J.B., Jorgensen, C., Petersen, R.K., Hallenborg, P., De Matteis, R., Boye, H.A., Petrovic, N., Enerback, S., Nedergaard, J., Cinti, S., et al. 2004. Retinoblastoma protein functions as a molecular switch determining white versus brown adipocyte differentiation. Proc. Natl. Acad. Sci. 101: 4112-4117.

Hany, T.F., Gharehpapagh, E., Kamel, E.M., Buck, A., HimmsHagen, J., and von Schulthess, G.K. 2002. Brown adipose tissue: A factor to consider in symmetrical tracer uptake in the neck and upper chest region. Eur. I. Nucl. Med. Mol. Imaging 29: 1393-1398.

Hasty, P., Bradley, A., Morris, J.H., Edmondson, D.G., Venuti, J.M., Olson, E.N., and Klein, W.H. 1993. Muscle deficiency and neonatal death in mice with a targeted mutation in the myogenin gene. Nature 364: 501-506.

Hata, K., Nishimura, R., Ikeda, F., Yamashita, K., Matsubara, T., Nokubi, T., and Yoneda, T. 2003. Differential roles of Smad1 and p38 kinase in regulation of peroxisome proliferatoractivating receptor $\gamma$ during bone morphogenetic protein 2-induced adipogenesis. Mol. Biol. Cell 14: 545-555.

Herzig, S., Long, F., Jhala, U.S., Hedrick, S., Quinn, R., Bauer, A., Rudolph, D., Schutz, G., Yoon, C., Puigserver, P., et al. 2001. CREB regulates hepatic gluconeogenesis through the coactivator PGC-1. Nature 413: 179-183.

Hondares, E., Mora, O., Yubero, P., Rodriguez de la Concepcion, M., Iglesias, R., Giralt, M., and Villarroya, F. 2006. Thiazolidinediones and rexinoids induce peroxisome proliferatoractivated receptor-coactivator (PGC)- $1 \alpha$ gene transcription: An autoregulatory loop controls PGC- $1 \alpha$ expression in adipocytes via peroxisome proliferator-activated receptor- $\gamma$ coactivation. Endocrinology 147: 2829-2838.

Jacks, T., Fazeli, A., Schmitt, E.M., Bronson, R.T., Goodell, M.A., and Weinberg, R.A. 1992. Effects of an Rb mutation in the mouse. Nature 359: 295-300.

Jin, W., Takagi, T., Kanesashi, S.N., Kurahashi, T., Nomura, T., Harada, J., and Ishii, S. 2006. Schnurri-2 controls BMPdependent adipogenesis via interaction with Smad proteins. Dev. Cell 10: 461-471.

Kajimura, S., Seale, P., Tomaru, T., Erdjument-Bromage, H., Cooper, M.P., Ruas, J.L., Chin, S., Tempst, P., Lazar, M.A., and Spiegelman, B.M. 2008. Regulation of the brown and white fat gene programs through a PRDM16/CtBP transcriptional complex. Genes \& Dev. 22: 1397-1409.

Kang, S., Bajnok, L., Longo, K.A., Petersen, R.K., Hansen, J.B., Kristiansen, K., and MacDougald, O.A. 2005. Effects of Wnt signaling on brown adipocyte differentiation and metabolism mediated by PGC-1 $\alpha$. Mol. Cell. Biol. 25: 1272-1282.

Karamanlidis, G., Karamitri, A., Docherty, K., Hazlerigg, D.G., and Lomax, M.A. 2007. C/EBP $\beta$ reprograms white 3T3-L1 preadipocytes to a Brown adipocyte pattern of gene expression. J. Biol. Chem. 282: 24660-24669.

Katagiri, T., Akiyama, S., Namiki, M., Komaki, M., Yamaguchi, A., Rosen, V., Wozney, J.M., Fujisawa-Sehara, A., and Suda, T. 1997. Bone morphogenetic protein-2 inhibits terminal differentiation of myogenic cells by suppressing the transcriptional activity of MyoD and myogenin. Exp. Cell Res. 230: 342-351.

Kim, J.K., Kim, H.J., Park, S.Y., Cederberg, A., Westergren, R., Nilsson, D., Higashimori, T., Cho, Y.R., Liu, Z.X., Dong, J., et al. 2005. Adipocyte-specific overexpression of FOXC2 prevents diet-induced increases in intramuscular fatty acyl CoA and insulin resistance. Diabetes 54: 1657-1663.

Klingenberg, M. 1999. Uncoupling protein-a useful energy dissipator. J. Bioenerg. Biomembr. 31: 419-430.

Klingenspor, M. 2003. Cold-induced recruitment of brown adipose tissue thermogenesis. Exp. Physiol. 88: 141-148.

Konishi, M., Mikami, T., Yamasaki, M., Miyake, A., and Itoh, N. 2000. Fibroblast growth factor-16 is a growth factor for embryonic brown adipocytes. J. Biol. Chem. 275: 12119-12122.

Kopecky, J., Clarke, G., Enerback, S., Spiegelman, B., and Kozak, L.P. 1995. Expression of the mitochondrial uncoupling protein gene from the aP2 gene promoter prevents genetic obesity. J. Clin. Invest. 96: 2914-2923.

Kopecky, J., Rossmeisl, M., Hodny, Z., Syrovy, I., Horakova, M., and Kolarova, P. 1996. Reduction of dietary obesity in aP2Ucp transgenic mice: Mechanism and adipose tissue morphology. Am. J. Physiol. 270: E776-E786.

Lee, E.Y., Chang, C.Y., Hu, N., Wang, Y.C., Lai, C.C., Herrup, K., Lee, W.H., and Bradley, A. 1992. Mice deficient for $\mathrm{Rb}$ are nonviable and show defects in neurogenesis and haematopoiesis. Nature 359: 288-294.

Lefterova, M.I., Zhang, Y., Steger, D.J., Schupp, M., Schug, J., Cristancho, A., Feng, D., Zhuo, D., Stoeckert Jr., C.J., Liu, X.S., et al. 2008. PPAR $\gamma$ and C/EBP factors orchestrate adipocyte biology via adjacent binding on a genome-wide scale. Genes \& Dev. 22: 2941-2952.

Leonardsson, G., Steel, J.H., Christian, M., Pocock, V., Milligan, S., Bell, J., So, P.W., Medina-Gomez, G., Vidal-Puig, A., White, R., et al. 2004. Nuclear receptor corepressor RIP140 regulates fat accumulation. Proc. Natl. Acad. Sci. 101: 8437-8442.

Lerin, C., Rodgers, J.T., Kalume, D.E., Kim, S.H., Pandey, A., and Puigserver, P. 2006. GCN5 acetyltransferase complex controls glucose metabolism through transcriptional repression of PGC-1 $\alpha$. Cell Metab. 3: 429-438.

Li, H.X., Luo, X., Liu, R.X., Yang, Y.J., and Yang, G.S. 2008. Roles of Wnt/ $\beta$-catenin signaling in adipogenic differentiation potential of adipose-derived mesenchymal stem cells. Mol. Cell. Endocrinol. 291: 116-124.

Lin, J., Wu, P.H., Tarr, P.T., Lindenberg, K.S., St-Pierre, J., Zhang, C.Y., Mootha, V.K., Jager, S., Vianna, C.R., Reznick, R.M., et al. 2004. Defects in adaptive energy metabolism with CNS-linked hyperactivity in PGC-1 $\alpha$ null mice. Cell 119: 121-135.

Lin, J., Handschin, C., and Spiegelman, B.M. 2005. Metabolic control through the PGC-1 family of transcription coactivators. Cell Metab. 1: 361-370.

Longo, K.A., Wright, W.S., Kang, S., Gerin, I., Chiang, S.H., Lucas, P.C., Opp, M.R., and MacDougald, O.A. 2004. Wnt10b inhibits development of white and brown adipose tissues. $J$. Biol. Chem. 279: 35503-35509.

Louet, J.F. and O'Malley, B.W. 2007. Coregulators in adipogenesis: What could we learn from the SRC (p160) coactivator family? Cell Cycle 6: 2448-2452.

Louet, J.F., Coste, A., Amazit, L., Tannour-Louet, M., Wu, R.C., Tsai, S.Y., Tsai, M.J., Auwerx, J., and O'Malley, B.W. 2006. 
Oncogenic steroid receptor coactivator-3 is a key regulator of the white adipogenic program. Proc. Natl. Acad. Sci. 103: $17868-17873$.

Lowell, B.B., S-Susulic, V., Hamann, A., Lawitts, J.A., HimmsHagen, J., Boyer, B.B., Kozak, L.P., and Flier, J.S. 1993. Development of obesity in transgenic mice after genetic ablation of brown adipose tissue. Nature 366: 740-742.

Mochizuki, N., Shimizu, S., Nagasawa, T., Tanaka, H., Taniwaki, M., Yokota, J., and Morishita, K. 2000. A novel gene, MEL1, mapped to $1 \mathrm{p} 36.3$ is highly homologous to the MDS1/EVI1 gene and is transcriptionally activated in t(1;3)(p36;q21)-positive leukemia cells. Blood 96: 3209-3214.

Modlich, U., Schambach, A., Brugman, M.H., Wicke, D.C., Knoess, S., Li, Z., Maetzig, T., Rudolph, C., Schlegelberger, B., and Baum, C. 2008. Leukemia induction after a single retroviral vector insertion in Evil or Prdm16. Leukemia 22: $1519-1528$.

Murray, S.S., Murray, E.J., Glackin, C.A., and Urist, M.R. 1993. Bone morphogenetic protein inhibits differentiation and affects expression of helix-loop-helix regulatory molecules in myoblastic cells. J. Cell. Biochem. 53: 51-60.

Nedergaard, J., Petrovic, N., Lindgren, E.M., Jacobsson, A., and Cannon, B. 2005. PPAR $\gamma$ in the control of brown adipocyte differentiation. Biochim. Biophys. Acta 1740: 293-304.

Nedergaard, J., Bengtsson, T., and Cannon, B. 2007. Unexpected evidence for active brown adipose tissue in adult humans. Am. J. Physiol. Endocrinol. Metab. 293: E444-E452. doi: 10.1152/ajpendo.00691.2006.

Nielsen, R., Pedersen, T.A., Hagenbeek, D., Moulos, P., Siersbaek, R., Megens, E., Denissov, S., Borgesen, M., Francoijs, K.J., Mandrup, S., et al. 2008. Genome-wide profiling of PPAR $\gamma:$ RXR and RNA polymerase II occupancy reveals temporal activation of distinct metabolic pathways and changes in RXR dimer composition during adipogenesis. Genes \& Dev. 22: 2953-2967.

Nishikata, I., Sasaki, H., Iga, M., Tateno, Y., Imayoshi, S., Asou, N., Nakamura, T., and Morishita, K. 2003. A novel EVIl gene family, MEL1, lacking a PR domain (MEL1S) is expressed mainly in $\mathrm{t}(1 ; 3)(\mathrm{p} 36 ; \mathrm{q} 21)$-positive AML and blocks G-CSFinduced myeloid differentiation. Blood 102: 3323-3332.

Otto, A., Schmidt, C., Luke, G., Allen, S., Valasek, P., Muntoni, F., Lawrence-Watt, D., and Patel, K. 2008. Canonical Wnt signalling induces satellite-cell proliferation during adult skeletal muscle regeneration. J. Cell Sci. 121: 2939-2950.

Picard, F., Gehin, M., Annicotte, J., Rocchi, S., Champy, M.F., O'Malley, B.W., Chambon, P., and Auwerx, J. 2002. SRC-1 and TIF2 control energy balance between white and brown adipose tissues. Cell 111: 931-941.

Polesskaya, A., Seale, P., and Rudnicki, M.A. 2003. Wnt signaling induces the myogenic specification of resident CD45+ adult stem cells during muscle regeneration. Cell 113: 841852.

Powelka, A.M., Seth, A., Virbasius, J.V., Kiskinis, E., Nicoloro, S.M., Guilherme, A., Tang, X., Straubhaar, J., Cherniack, A.D., Parker, M.G., et al. 2006. Suppression of oxidative metabolism and mitochondrial biogenesis by the transcriptional corepressor RIP140 in mouse adipocytes. J. Clin. Invest. 116: 125-136.

Pownall, M.E., Gustafsson, M.K., and Emerson Jr., C.P. 2002. Myogenic regulatory factors and the specification of muscle progenitors in vertebrate embryos. Annu. Rev. Cell Dev. Biol. 18: $747-783$.

Puigserver, P., Wu, Z., Park, C.W., Graves, R., Wright, M., and Spiegelman, B.M. 1998. A cold-inducible coactivator of nuclear receptors linked to adaptive thermogenesis. Cell 92: 829-839.
Rea, S., Eisenhaber, F., O'Carroll, D., Strahl, B.D., Sun, Z.W., Schmid, M., Opravil, S., Mechtler, K., Ponting, C.P., Allis, C.D., et al. 2000. Regulation of chromatin structure by sitespecific histone H3 methyltransferases. Nature 406: 593599.

Reshef, R., Maroto, M., and Lassar, A.B. 1998. Regulation of dorsal somitic cell fates: BMPs and Noggin control the timing and pattern of myogenic regulator expression. Genes \& Dev. 12: 290-303.

Ribeiro, M.O., Carvalho, S.D., Schultz, J.J., Chiellini, G., Scanlan, T.S., Bianco, A.C., and Brent, G.A. 2001. Thyroid hormone-sympathetic interaction and adaptive thermogenesis are thyroid hormone receptor isoform-specific. J. Clin. Invest. 108: 97-105.

Rosen, E.D. and MacDougald, O.A. 2006. Adipocyte differentiation from the inside out. Nature Reviews 7: 885-896.

Rosen, E.D. and Spiegelman, B.M. 2000. Molecular regulation of adipogenesis. Annu. Rev. Cell Dev. Biol. 16: 145-171.

Rosen, E.D., Sarraf, P., Troy, A.E., Bradwin, G., Moore, K., Milstone, D.S., Spiegelman, B.M., and Mortensen, R.M. 1999. PPAR $\gamma$ is required for the differentiation of adipose tissue in vivo and in vitro. Mol. Cell 4: 611-617.

Ross, S.E., Hemati, N., Longo, K.A., Bennett, C.N., Lucas, P.C., Erickson, R.L., and MacDougald, O.A. 2000. Inhibition of adipogenesis by Wnt signaling. Science 289: 950-953.

Rothwell, N.J. and Stock, M.J. 1979. Combined effects of cafeteria and tube-feeding on energy balance in the rat. Proc. Nutr. Soc. 38: 5A.

Scheffler, I.E. 1999. Mitochondria. Wiley-Liss, New York.

Schultz, D.C., Ayyanathan, K., Negorev, D., Maul, G.G., and Rauscher III, F.J. 2002. SETDB1: A novel KAP-1-associated histone $\mathrm{H} 3$, lysine 9-specific methyltransferase that contributes to HP1-mediated silencing of euchromatic genes by KRAB zinc-finger proteins. Genes \& Dev. 16: 919932.

Scime, A., Grenier, G., Huh, M.S., Gillespie, M.A., Bevilacqua, L., Harper, M.E., and Rudnicki, M.A. 2005. Rb and p107 regulate preadipocyte differentiation into white versus brown fat through repression of PGC-1 $\alpha$. Cell Metab. 2: 283-295

Seale, P., Kajimura, S., Yang, W., Chin, S., Rohas, L.M., Uldry, M., Tavernier, G., Langin, D., and Spiegelman, B.M. 2007. Transcriptional control of brown fat determination by PRDM16. Cell Metab. 6: 38-54.

Seale, P., Bjork, B., Yang, W., Kajimura, S., Chin, S., Kuang, S., Scime, A., Devarakonda, S., Conroe, H.M., Erdjument-Bromage, H., et al. 2008. PRDM16 controls a brown fat/skeletal muscle switch. Nature 454: 961-967.

Seth, A., Steel, J.H., Nichol, D., Pocock, V., Kumaran, M.K., Fritah, A., Mobberley, M., Ryder, T.A., Rowlerson, A., Scott, J., et al. 2007. The transcriptional corepressor RIP140 regulates oxidative metabolism in skeletal muscle. Cell Metab. 6: 236-245.

Shing, D.C., Trubia, M., Marchesi, F., Radaelli, E., Belloni, E., Tapinassi, C., Scanziani, E., Mecucci, C., Crescenzi, B., Lahortiga, I., et al. 2007. Overexpression of sPRDM16 coupled with loss of p53 induces myeloid leukemias in mice. $J$. Clin. Invest. 117: 3696-3707.

Sottile, V. and Seuwen, K. 2000. Bone morphogenetic protein-2 stimulates adipogenic differentiation of mesenchymal precursor cells in synergy with BRL 49653 (rosiglitazone). FEBS Lett. 475: 201-204.

Taha, M.F., Valojerdi, M.R., and Mowla, S.J. 2006. Effect of bone morphogenetic protein-4 (BMP-4) on adipocyte differentiation from mouse embryonic stem cells. Anat. Histol. Embryol. 35: 271-278. 
Tang, Q.Q., Otto, T.C., and Lane, M.D. 2004. Commitment of C3H10T1/2 pluripotent stem cells to the adipocyte lineage. Proc. Natl. Acad. Sci. 101: 9607-9611.

Tang, W., Zeve, D., Suh, J.M., Bosnakovski, D., Kyba, M., Hammer, R.E., Tallquist, M.D., and Graff, J.M. 2008. White fat progenitor cells reside in the adipose vasculature. Science 322: $583-586$.

Tatsumi, M., Engles, J.M., Ishimori, T., Nicely, O., Cohade, C., and Wahl, R.L. 2004. Intense ${ }^{18}$ F-FDG uptake in brown fat can be reduced pharmacologically. J. Nucl. Med. 45: 11891193.

Timmons, J.A., Wennmalm, K., Larsson, O., Walden, T.B., Lassmann, T., Petrovic, N., Hamilton, D.L., Gimeno, R.E., Wahlestedt, C., Baar, K., et al. 2007. Myogenic gene expression signature establishes that brown and white adipocytes originate from distinct cell lineages. Proc. Natl. Acad. Sci. 104: 4401-4406.

Tiraby, C., Tavernier, G., Lefort, C., Larrouy, D., Bouillaud, F., Ricquier, D., and Langin, D. 2003. Acquirement of brown fat cell features by human white adipocytes. J. Biol. Chem. 278: 33370-33376.

Tomlinson, E., Fu, L., John, L., Hultgren, B., Huang, X., Renz, M., Stephan, J.P., Tsai, S.P., Powell-Braxton, L., French, D., et al. 2002. Transgenic mice expressing human fibroblast growth factor-19 display increased metabolic rate and decreased adiposity. Endocrinology 143: 1741-1747.

Tontonoz, P., Hu, E., and Spiegelman, B.M. 1994. Stimulation of adipogenesis in fibroblasts by PPAR $\gamma 2$, a lipid-activated transcription factor. Cell 79: 1147-1156.

Trievel, R.C., Beach, B.M., Dirk, L.M., Houtz, R.L., and Hurley, J.H. 2002. Structure and catalytic mechanism of a SET domain protein methyltransferase. Cell 111: 91-103.

Tseng, Y.H., Kokkotou, E., Schulz, T.J., Huang, T.L., Winnay, J.N., Taniguchi, C.M., Tran, T.T., Suzuki, R., Espinoza, D.O., Yamamoto, Y., et al. 2008. New role of bone morphogenetic protein 7 in brown adipogenesis and energy expenditure. Nature 454: 1000-1004.

Tsukiyama-Kohara, K., Poulin, F., Kohara, M., DeMaria, C.T., Cheng, A., Wu, Z., Gingras, A.C., Katsume, A., Elchebly, M., Spiegelman, B.M., et al. 2001. Adipose tissue reduction in mice lacking the translational inhibitor 4E-BP1. Nat. Med. 7: $1128-1132$.

Uldry, M., Yang, W., St-Pierre, J., Lin, J., Seale, P., and Spiegelman, B.M. 2006. Complementary action of the PGC-1 coactivators in mitochondrial biogenesis and brown fat differentiation. Cell Metab. 3: 333-341.

Walden, T.B., Timmons, J.A., Keller, P., Nedergaard, J., and Cannon, B. 2009. Distinct expression of muscle-specific microRNAs (myomirs) in brown adipocytes. J. Cell. Physiol. 218: 444-449.

Weber, W.A. 2004. Brown adipose tissue and nuclear medicine imaging. J. Nucl. Med. 45: 1101-1103.

Wilson-Fritch, L., Nicoloro, S., Chouinard, M., Lazar, M.A., Chui, P.C., Leszyk, J., Straubhaar, J., Czech, M.P., and Corvera, S. 2004. Mitochondrial remodeling in adipose tissue associated with obesity and treatment with rosiglitazone. J. Clin. Invest. 114: 1281-1289.

Wu, Z., Rosen, E.D., Brun, R., Hauser, S., Adelmant, G., Troy, A.E., McKeon, C., Darlington, G.J., and Spiegelman, B.M. 1999. Cross-regulation of C/EBP $\alpha$ and PPAR $\gamma$ controls the transcriptional pathway of adipogenesis and insulin sensitivity. Mol. Cell 3: 151-158.

Xue, B., Rim, J.S., Hogan, J.C., Coulter, A.A., Koza, R.A., and Kozak, L.P. 2007. Genetic variability affects the development of brown adipocytes in white fat but not in interscapular brown fat. I. Lipid Res. 48: 41-51.
Xue, Y., Cao, R., Nilsson, D., Chen, S., Westergren, R., Hedlund, E.M., Martijn, C., Rondahl, L., Krauli, P., Walum, E., et al. 2008. FOXC2 controls Ang-2 expression and modulates angiogenesis, vascular patterning, remodeling, and functions in adipose tissue. Proc. Nat1. Acad. Sci. 105: 10167-10172.

Yeung, H.W., Grewal, R.K., Gonen, M., Schoder, H., and Larson, S.M. 2003. Patterns of ${ }^{18}$ F-FDG uptake in adipose tissue and muscle: A potential source of false-positives for PET. J. Nucl. Med. 44: 1789-1796.

Yoshida, M., Nosaka, K., Yasunaga, J., Nishikata, I., Morishita, K., and Matsuoka, M. 2004. Aberrant expression of the MEL1S gene identified in association with hypomethylation in adult T-cell leukemia cells. Blood 103: 2753-2760. 


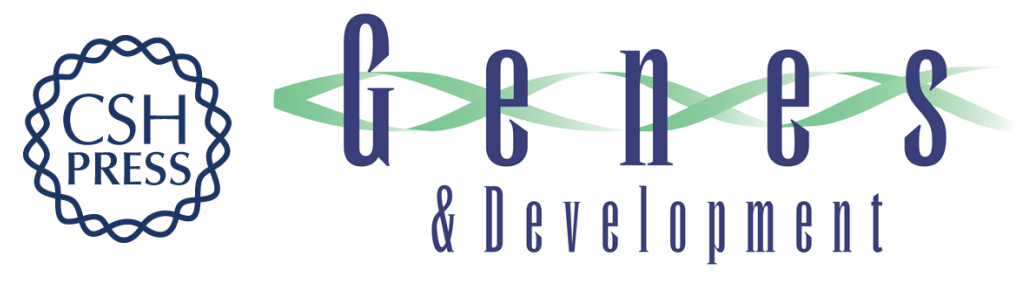

\section{Transcriptional control of brown adipocyte development and physiological function- - of mice and men}

Patrick Seale, Shingo Kajimura and Bruce M. Spiegelman

Genes Dev. 2009, 23:

Access the most recent version at doi:10.1101/gad.1779209

References This article cites 108 articles, 38 of which can be accessed free at: http://genesdev.cshlp.org/content/23/7/788.full.html\#ref-list-1

License

Email Alerting

Receive free email alerts when new articles cite this article - sign up in the box at the top Service right corner of the article or click here.

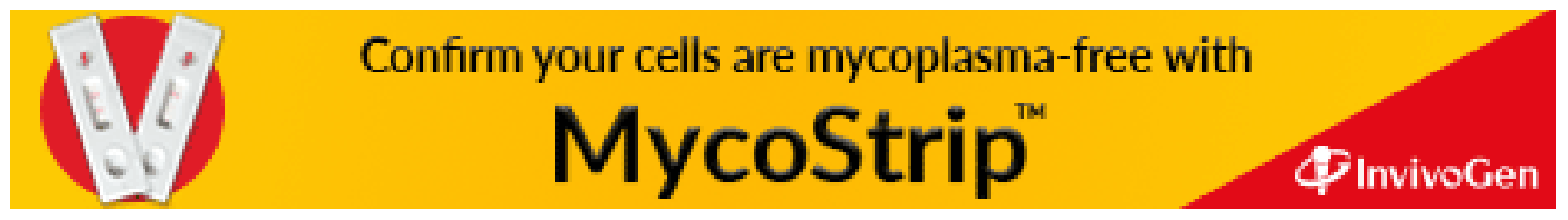

